\title{
Hybrid Materials Based on Bentonite Functionalized with Amine Groups via the Hydrolytic Sol-Gel Method
}

\author{
Thales J. Gilberto, Liziane Marçal, Jhonatan M. Silva, Lucas A. Rocha, Katia J. Ciuffi, \\ Emerson H. Faria and Eduardo J. Nassar*
}

\author{
Universidade de Franca, Av. Dr. Armando Salles Oliveira, 201 Pq. Universitário, \\ CP 82, 14404-600 Franca-SP, Brazil
}

\begin{abstract}
Bentonite is a natural clay that presents characteristics such as good capacity to exchange cations, large specific surface area, large porosity, and possibility to undergo intercalation and/or functionalization. This work reports on bentonite functionalization with organomodified alkoxides. Functionalization afforded hybrid materials displaying desirable properties for adsorption of chromium trivalent ions. Infrared absorption spectroscopy, X-ray powder diffraction, thermal analysis, specific surface area analysis, and adsorption experiments with methylene blue helped to characterize the materials and evaluate their cationic exchange capability. These techniques evidenced functionalization of the Brazilian bentonite. Kinetic and equilibrium experiments on the adsorption of chromium trivalent ions aided determination of the equilibrium time of kinetic adsorption isotherms and revealed whether the functionalized matrices adsorbed chromium trivalent ions. Chromium displayed S1 type adsorption isotherms, which confirmed that adsorption capacity originated from cooperative forces between the adsorbate and the hybrid adsorbents.
\end{abstract}

Keywords: clay, bentonite, adsorption, hybrid material, amine alkoxide

\section{Introduction}

Bentonite or bentonite clay has found wide application in professional drilling, civil engineering, and geology. Basically, it helps to maintain stable holes during drilling by expanding contact with water and forming a gel. Bentonite presents other properties such as very low permeability and high cation exchange capacity, which are important in the area of environmental engineering and these properties render the clay a barrier to heavy metal contaminants. ${ }^{1}$

Several works have reported on clay modification and on clay adsorption capacity for environmental use as adsorbents. ${ }^{2-12}$ In addition, clay materials can undergo intercalation reactions and/or functionalization of its interlayers and/or surface area, to afford hybrid materials. The - $\mathrm{OH}$ groups present in the clay edges will react with silane through condensation reactions via the sol-gel method. Nucleophilic attack from the interlayer siloxane hydroxyls or from water in hydrated cations can induce hydrolysis, and silanol and $\mathrm{Mg}-\mathrm{OH}$ present in lateral edge sites or in clay surface defects can favor condensation. ${ }^{13-15}$ Clay functionalization with organic compounds can add

\footnotetext{
*e-mail: eduardo.nassar@unifran.edu.br
}

new properties to hybrid materials and increase chemical affinity between adsorbent and adsorbate, consolidating their use for environmental purposes. ${ }^{16}$ Study of natural clay adsorption capacity and comparison of this capacity with the adsorption capacity of hybrid clay materials can contribute to entrapping contaminants in the physical environment of the clay, thereby enabling treatment of industrial effluents with modified clays.

The use of hybrid organic-inorganic compounds has relied on their enhanced specific properties as compared with the properties of the corresponding unmodified materials. Hybrid materials have promising application in the industry and in scientific research. ${ }^{16-20}$

This work studied functionalization of bentonite (BEN) with the organomodified alkoxides (3-aminopropyl) triethoxysilane (APTES), $N^{1}$-(3-trimethoxysilylpropyl) diethylenetriamine (TMPT), and $N$-[3-(trimethoxysilyl) propyl]ethylenediamine (TMPO), to obtain the hybrid materials BEN-APTES, BEN-TMPT, and BEN-TMPO. These materials displayed desirable properties for adsorption of chromium trivalent ions. Infrared absorption spectroscopy, X-ray powder diffraction, thermal analysis, specific surface area analysis, and adsorption experiments with methylene blue aided characterization 
of the materials and evaluation of their cationic exchange capability (CEC).

\section{Experimental}

\section{Bentonite functionalization}

The bentonite used in this work was commercially available from the company MI SWACO SA (Boa Vista, Brazil) with the nomenclature Bentonite Drescongel. Distilled water was used in all the experiments. Ethanol and the alkoxides APTS, TMPO and TMPT were purchased from Sigma-Aldrich (Saint Louis, USA). Figure 1 shows the structural formulas of the alkoxides used herein.

The hybrid materials were prepared by the procedure described by the SOL-GEL Group of the University of Franca. ${ }^{21-24}$ Before functionalization with organosilanes, BEN was pre-expanded with distilled water. To this end, $5.0 \mathrm{~g}$ of clay was added to $100.0 \mathrm{~mL}$ of distilled water and vigorously stirred for $1 \mathrm{~h}$. Next, $2.0 \mathrm{~mL}$ of one of the alkoxides was added, and the reaction was allowed to proceed under stirring at room temperature for $48 \mathrm{~h}$. The material was then washed with ethanol and water, which was followed by drying at $100{ }^{\circ} \mathrm{C}$ for $24 \mathrm{~h}$. The samples were kept in desiccators.

\section{Adsorption by bath method}

Kinetic studies were carried out to determine the time of matrix saturation. The studies were conducted in eight test tubes containing $50.0 \mathrm{mg}$ of the adsorbent and $5.0 \mathrm{~mL}$ of $\mathrm{Cr}^{\text {III }}$ solution $\mathrm{pH}$ ca. 6 at a concentration of $0.003 \mathrm{~mol} \mathrm{~L}^{-1}$. The test tubes were stirred for 1, 5, 10, 20, 30, 60, and $90 \mathrm{~min}$.

\section{Characterization techniques}

Fourier transform infrared absorption spectroscopy (FTIR) was conducted on a Frontier PerkinElmer spectrometer (New York, USA); the spectra were acquired in the attenuated total reflection (ATR) mode, and the samples were diluted in $\mathrm{KBr}$. To acquire the spectra, the samples were scanned 16 times at a resolution of $4 \mathrm{~cm}^{-1}$, from 4000 to $500 \mathrm{~cm}^{-1}$.

X-ray diffraction (XRD) patterns of the powder samples were recorded at room temperature on a Rigaku Geigerflex D/max-c diffractometer (Tokyo, Japan) with monochromated $\mathrm{Cu} \mathrm{K}_{\alpha}$ radiation $(\lambda=1.54 \AA$ ). The XRD patterns were recorded in the $2 \theta$ range from 3 to $70^{\circ}$ at a resolution of $0.05^{\circ}$. The temperature and humidity of the XRD room was controlled by an air conditioner and a dehumidifier.

Thermogravimetry (TGA) and derivative thermogravimetry (DTG) analysis was carried out (Thermal Analyst 2100-TA Instruments SDT 2960 simultaneous DTA-TGA, New Castle, USA) in nitrogen atmosphere at a heating rate of $20{ }^{\circ} \mathrm{C} \mathrm{min}-1$, from 25 to $900{ }^{\circ} \mathrm{C}$; powder samples were employed during the analysis.

Specific surface areas were determined by applying the Brunauer, Emett and Teller (BET) method to the corresponding nitrogen adsorption data at $-196{ }^{\circ} \mathrm{C}$, obtained by using a Micrometrics ASAP 2020 physical adsorption analyzer (Norcross, USA). The samples were previously degassed in situ at room temperature for $1 \mathrm{~h}$, at a pressure lower than $50 \mu \mathrm{m} \mathrm{Hg}$. The nitrogen adsorption data were obtained by using $0.2 \mathrm{~g}$ of the sample.

Electronic spectra of the materials were recorded on a Hewlett-Packard 8453 diode array UV-Vis spectrophotometer (Palo Alto, EUA). Samples were placed in a cell with path length of $1.0 \mathrm{~cm}$.

Cation exchange capacity (CEC) and specific surface (SS) of the material

CEC and SS were determined by the methylene blue method described by Yukselen and Kaya. ${ }^{25}$ Briefly, $1.0 \mathrm{~mL}$ portions of methylene blue were successively added to the

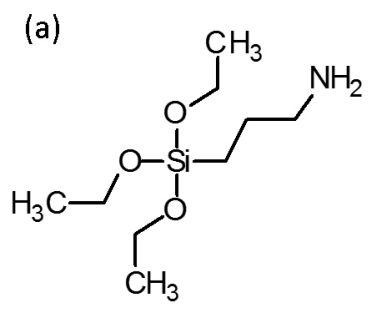

(b)

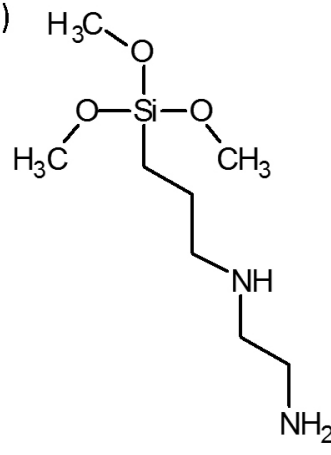

(c)<smiles>CO[Si](CCCNCCNCCN)(OC)OC</smiles>

Figure 1. Structural formulas of the alkoxides (a) APTES; (b) TMPT; and (c) TMPO. 
clay sample until the clay became saturated. Saturation was evident from formation of a blue circle around the solid portion.

Equations 1 and 2 show how to obtain CEC and SS from the volume of methylene blue that was necessary to saturate the sample:

$\mathrm{CEC}=\mathrm{C} \times \mathrm{V} \times 100 / \mathrm{W}_{\mathrm{a}}$

where CEC $=$ cation exchange capacity (meq per $100.0 \mathrm{~g}$ of dry clay), $\mathrm{C}=$ methylene blue concentration $\left(\mathrm{meq} \mathrm{L}^{-1}\right)$, $\mathrm{V}=$ methylene volume $(\mathrm{L})$ and $\mathrm{W}_{\mathrm{a}}=$ dry clay mass $(\mathrm{g})$.

$\mathrm{SS}=\mathrm{F}_{\mathrm{a}} \times \mathrm{CEC}$

where SS $=$ specific surface $\left(\mathrm{m}^{2} \mathrm{~g}^{-1}\right)$ and $\mathrm{F}_{\mathrm{a}}=$ methylene blue factor (7.8043).

\section{Results and Discussion}

Fourier transform infrared spectroscopy

Figure 2 illustrates the FTIR spectra of commercial bentonite (BEN) and of the functionalized bentonites (BEN-APTS, BEN-TMPT, and BEN-TMPO) investigated in this work.

The spectrum (a) in Figure 2 presents the characteristic vibrational modes of $\mathrm{BEN}$, as discussed in the literature., 9,26,27 As for the spectra of BEN-APTS, BEN-TMPT, and BEN-TMPO (spectra b-d in Figure 2), they display bands between 2929 and $2795 \mathrm{~cm}^{-1}$, ascribed to $\mathrm{CH} / \mathrm{NH}$ groups, and at 1567 and $1330 \mathrm{~cm}^{-1}$, ascribed to amine groups $\left(\mathrm{NH}_{2}\right)$. The FTIR spectra indicated functionalization of bentonite with the alkoxides. Table 1 lists the vibrational modes present in BEN, BEN-APTS, BEN-TMPT, and BEN-TMPO.

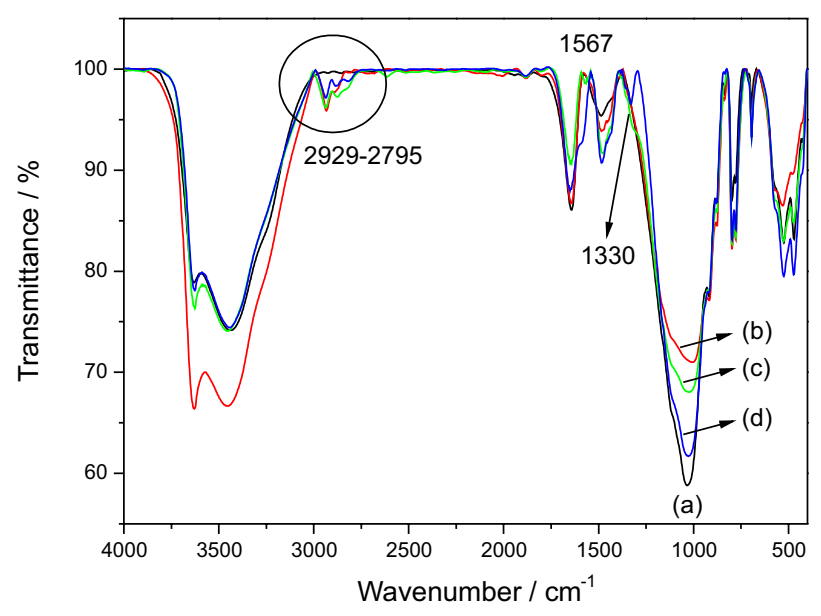

Figure 2. FTIR spectra of (a) BEN and of the functionalized bentonites (b) BEN-APTS; (c) BEN-TMPT; and (d) BEN-TMPO.

The absorption bands in the region between 3600 and $3400 \mathrm{~cm}^{-1}$ corresponded to $-\mathrm{OH}$ stretching. The peaks arising in the region of $1600 \mathrm{~cm}^{-1}$ corresponded to deformation of interlayer and adsorbed water. ${ }^{9,27-29}$ The bands at 1029 and $790 \mathrm{~cm}^{-1}$ referred to $\mathrm{Si}-\mathrm{O}-\mathrm{Si}$ and $\mathrm{Si}-\mathrm{O}$, respectively, and attested to the presence of a tetrahedral silica layer. ${ }^{30,31}$

The $-\mathrm{OH}$ groups inside and in the edge regions of the clay gave rise to the characteristic infrared $-\mathrm{OH}$ bands of BEN at 3630 and $3439 \mathrm{~cm}^{-1}$. These bands shifted to 3629 and $3454 \mathrm{~cm}^{-1}, 3626$ and $3442 \mathrm{~cm}^{-1}$, and 3626 and $3455 \mathrm{~cm}^{-1}$ in the spectra of BEN-APTS, BEN-TMPO, and BEN-TMPT, respectively, which evidenced BEN functionalization. The lower intensity of these bands was yet another indication of water removal from BEN during the functionalization process. ${ }^{32}$

The Al-OH vibration modes were shifted in the case of the samples BEN-TMPO and BEN-TMPT, which was caused by the presence of silane molecules in these

Table 1. Assignments of the FTIR bands present in the spectra of commercial and functionalized bentonites

\begin{tabular}{lccccc}
\hline Assignment & BEN $^{19}$ & BEN & BEN-APTS & BEN-TMPO & BEN-TMPT \\
\hline$v(\mathrm{OH})_{\text {intra }}$ & 3622 & 3630 & 3629 & 3626 & 3626 \\
$v \mathrm{H}-\mathrm{O}-\mathrm{H}$ & 3450 & 3440 & 3455 & 3443 & 3456 \\
$\delta \mathrm{H}-\mathrm{O}-\mathrm{H}$ & 1633 & 1642 & 1644 & 1650 & 1650 \\
$v \mathrm{CH}_{2} / \mathrm{CH}_{3}$ & - & - & $2929-2795$ & $2929-2795$ & $2929-2795$ \\
$v \mathrm{NH}_{2}$ & - & - & 1567,1330 & 1567,1330 & 1567,1330 \\
$v \mathrm{Si}-\mathrm{O}-\mathrm{Si}$ & 1033 & 1019 & 1004 & 1010 & 1030 \\
$v \mathrm{Al}-\mathrm{OH}$ & 916 & 917 & 877 & 877 \\
$\mathrm{SiO}{ }_{2}$ or quartz & 914 & 797 & 797 & 797 & 797 \\
$\mathrm{Si}-\mathrm{O} \mathrm{Si}-\mathrm{O}-\mathrm{Al}$ & 791 & 712,695 & 694 & 694 & 594 \\
$\mathrm{Si}-\mathrm{O}$ Si-O-Al & 693 & 525,471 & 530 & 525 & 526 \\
$\mathrm{Si}-\mathrm{O}$ Si-O-Si & 538 & 425 & 480 & 472 & 473 \\
\hline
\end{tabular}


materials. The hydrogen bonds from the amine groups of TMPO and TMPT and/or the - $\mathrm{OH}$ groups arising from incomplete hydrolysis of these alkoxides can influence the $\mathrm{Al}-\mathrm{OH}$ and/or $\mathrm{Mg}-\mathrm{OH}$ bonding. These shifts do not occur in the case of BEN-APTS because APTS contains only one amine group, whereas TMPO and TMPT present two and three amine groups, respectively.

\section{X-ray diffraction}

Figure 3 shows the XRD patterns of BEN, BEN-APTS, BEN-TMPT, and BEN-TMPO.

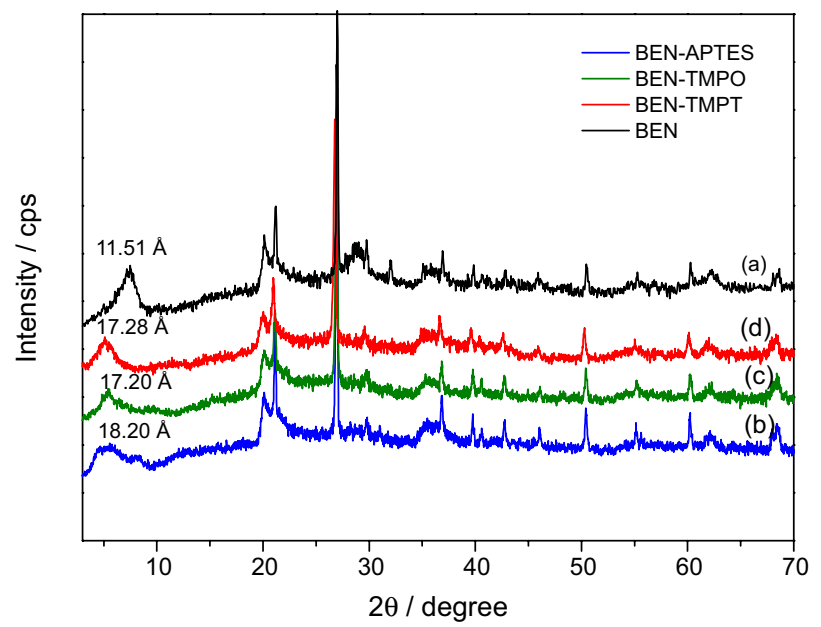

Figure 3. XRD patterns of (a) BEN; (b) BEN-APTS; (c) BEN-TMPO; and (d) BEN-TMPT.

The diffractograms show the presence of montmorillonite $\left(2 \theta=7.56^{\circ}\right.$ and $19.83^{\circ}$ card 2-9 Crystallographica SearchMatch) and quartz ( $2 \theta=26.47^{\circ}$ card 1-649 Crystallographica Search-Match), typical of this type of clay in which smectite is the predominant clay mineral. ${ }^{27,33,34}$ The interlayer distance was calculated by Bragg's law $(\mathrm{n} \lambda=2 \mathrm{~d} \operatorname{sen} \theta)$. BEN gave a smaller interlayer distance than the distance described by Vieira et al. ${ }^{35}$ (around 11.51 and $15 \AA$, respectively). Other authors found an interlayer distance of 8 and $9 \AA$ when they used 3-mercaptopropyltrimethoxy silane ${ }^{27}$ and pillaring with $\mathrm{Al}$ and $\mathrm{Co}^{36}$ to modify bentonite, respectively. The bentonite source and the functionalizing agent probably accounted for the different regions of the clays, namely interlayer, edge, and surface, evidenced by FTIR and XRD results regarding distance.

BEN presented a basal spacing of $11.51 \AA$, which changed to $18.20,17.50$, and $17.28 \AA$ after functionalization with the alkoxides APTES, TMPO, and TMPT, respectively. The larger basal spacing in BEN-APTES, BEN-TMPO, and BEN-TMPT indicated that the alkoxide occupied the interlayer space in the clay. The other characteristic BEN peaks remained unaffected, revealing that functionalization did not modify the structure of the clay. ${ }^{36}$

\section{Thermogravimetric curves}

Thermogravimetric analysis helped to investigate decomposition of the organic compounds incorporated into the bentonite matrix and confirmed the results from the FTIR spectra and XRD patterns. Figures 4 and 5 show the thermogravimetric curves and the corresponding derivative curves obtained for the samples BEN, BEN-APTS, BEN-TMPT, and BEN-TMPO.

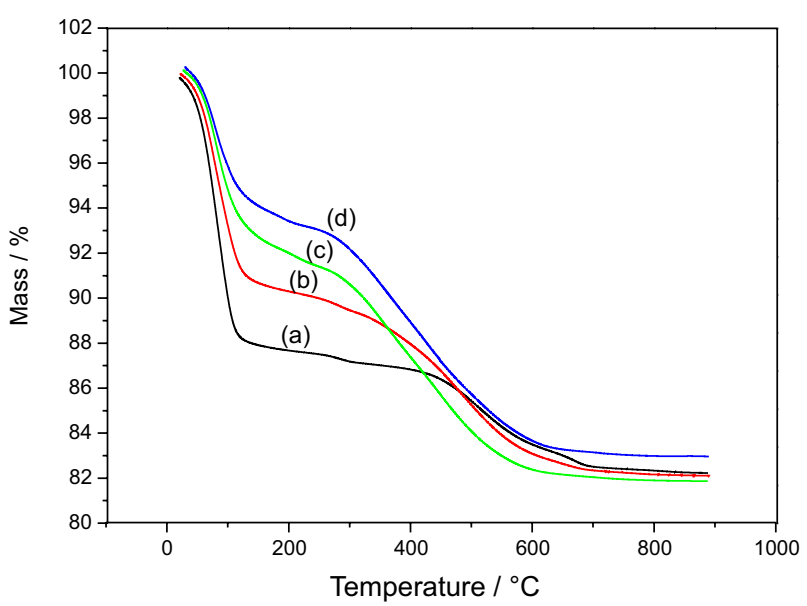

Figure 4. TGA curves obtained for (a) BEN; (b) BEN-APTES; (c) BEN-TMPT; and (d) BEN-TMPO.

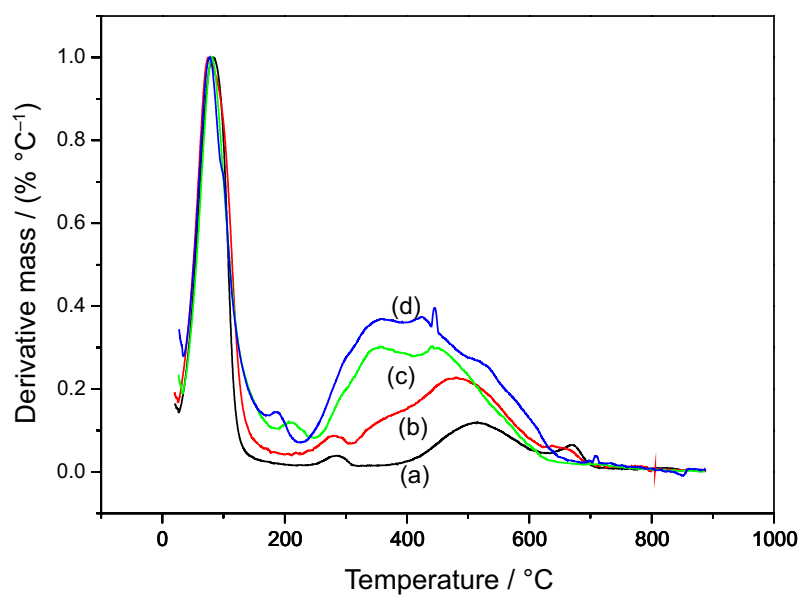

Figure 5. DTG curves obtained for (a) BEN; (b) BEN-APTES; (c) BEN-TMPT; and (d) BEN-TMPO.

The TGA and DTG curves presented in Figures 4 and 5 showed the weight loss stages experienced by BEN and the functionalized bentonites. The first mass loss occurred below $250{ }^{\circ} \mathrm{C}$. It was ascribed to loss of physically adsorbed water and corresponded to 11.0, 9.7, 11.9, and $10.5 \%$ weight loss for BEN, BEN-APTES, BEN-TMPO, and BEN-TMPT, respectively. The second mass loss, around 
$285^{\circ} \mathrm{C}$, was assigned to loss of adsorbed water and release of exchangeable water coordinated to cations. ${ }^{37}$ The main weight loss occurred at temperatures above $250{ }^{\circ} \mathrm{C}$. BEN lost $4.3 \%$ of its mass as a result of dehydroxylation. As for the functionalized bentonites, BEN-APTS, BEN-TMPO, BEN-TMPT lost $6.5,13.1$, and $15.1 \%$ of their mass in this stage, respectively, because of decomposition of the organic groups and dehydroxylation. Knowing that dehydroxylation corresponded to ca. $4 \%$ mass loss in commercial bentonite, functionalization corresponded to $2.5,9.1$, and $11.1 \%$ of the samples BEN-APTS, BEN-TMPO, and BEN-TMPT, respectively. Therefore, functionalization with di- and triamine silane precursors present a higher percentage that can be ascribed to silane precursors.

Surface area, cation exchange capacity (CEC), and specific surface (SS)

The surface area and porosity of the materials was determined by BET analysis. According to IUPAC (International Union of Pure and Applied Chemistry), classification of the hysteresis loops refers to the texture of a material. In this case, the materials belonged to class $\mathrm{H} 1$, associated with porous materials that consisted of well-defined uniform cylindrical pores or nearly compact agglomerate spheres. Also according to IUPAC, type IV isotherms correspond to a mesoporous material. ${ }^{38}$ Table 2 presents the surface areas, CEC, and SS values obtained for BEN, BEN-APTS, BEN-TMPT, and BEN-TMPO.

Table 2. Surface area, CEC, and SS values obtained for commercial bentonite and functionalized bentonites

\begin{tabular}{lcccc}
\hline Sample & $\begin{array}{c}\text { Surface area } \\
\text { BET } /\left(\mathrm{m}^{2} \mathrm{~g}^{-1}\right)\end{array}$ & $\begin{array}{c}\text { Methylene } \\
\text { blue } / \mathrm{mL}\end{array}$ & $\begin{array}{c}\text { CEC } \\
(\mathrm{meq} \text { } \text { er } 100 \mathrm{~g})\end{array}$ & $\begin{array}{c}\mathrm{SS} / \\
\left(\mathrm{m}^{2} \mathrm{~g}^{-1}\right)\end{array}$ \\
\hline BEN & 57 & 3.40 & 68 & 531 \\
BEN-APTS & 15 & 0.65 & 13 & 101 \\
BEN-TMPO & 37 & 0.20 & 4 & 31 \\
BEN-TMPT & 16 & 0.25 & 5 & 39 \\
\hline
\end{tabular}

Literature works have shown that the surface area of bentonite can vary. Bentonite is not pure clay. In fact, in its composition there is a mixture of clay minerals of different types like tetrahedral-octahedral-tetrahedral (T-O-T) clays such as montmorillonite, hectorite, and others, and quartz, the main component of this clay. The proportion of these minerals in bentonite varies depending on the deposit. The surface area obtained in this work agrees with surface area values reported in other papers. . $8,30,35,39$

The surface area of BEN-APTS, BEN-TMPT, and BEN-TMPO decreased as compared with the surface area of BEN. This happened probably because the organic compounds occupied active bentonite sites, which reduced the number of active sites available for gas adsorption. The increase in basal spacing was not directly related to the increase in surface area. ${ }^{28,30,40}$ The surface area results corroborated the XRD, FTIR, and TGA data and attested to clay functionalization.

Table 2 also shows the specific surface area measured by the $\mathrm{N}_{2}$ adsorption and the methylene blue (MB) methods. $\mathrm{N}_{2}$ adsorption gave lower surface area values than the surface area values measured by the MB method. This difference probably resulted from the weak van der Waals bonding established between the interlayer organic compounds under the dry conditions applied during gas adsorption measurements. The gas molecules were not able to enter the tightly bound bentonite layers, so only these molecules only adsorbed onto the external clay surface.

In contrast, the MB method employed wet conditions. Hence, ions or water intercalated into the inner bentonite layers and allowed for measurement of the external and internal surface area, as discussed in the literature..$^{25}$ One literature paper has also proposed that the negative charge of $\mathrm{Si}-\mathrm{O}$ interacts with the positive charge of the methylene blue ion. ${ }^{41}$ Compared with BEN, the smaller surface areas of BEN-APTS, BEN-TMPO, and BEN-TMPT measured by the $\mathrm{N}_{2}$ adsorption and MB methods attested to BEN functionalization.

CEC obtained by the MB method provided a measure of the cation exchange capacity of the clays. ${ }^{42} \mathrm{CEC}$ obtained for BEN was higher than CEC obtained for the functionalized bentonites. Therefore, the presence of alkoxides in BEN reduced the cation exchange capacity of the clay, probably because the silanes molecules on the edge of the clay blocked access to the interlayer space and reduced the cation exchange capacity, as observed by us in another work..$^{13}$

The Brazilian bentonite clay from Paraíba State, Brazil has CEC of about 87.53 meq per $100 \mathrm{~g}$ of clay as estimated by ammonium cation exchange. ${ }^{43}$ Another work has reported CEC of 74 meq per $100 \mathrm{~g}$ of clay for bentonite on the basis of flame emission spectrophotometry. ${ }^{44}$ The CEC value of $68 \mathrm{meq}$ per $100 \mathrm{~g}$ of clay obtained here can be attributed to the fact that BEN was not submitted to any treatment.

\section{Adsorption study}

\section{Kinetics}

Figure 6 illustrates the adsorption kinetics study conducted for BEN, BEN-APTS, BEN-TMPT, and BEN-TMPO at $\mathrm{Cr}^{\mathrm{III}}$ ion concentration of $0.06 \mathrm{~mol} \mathrm{~L}^{-1}$.

Adsorption reached equilibrium at $30 \mathrm{~min}$ for all the adsorbents. At this point, the amounts of $\mathrm{Cr}^{\mathrm{III}}$ ions being adsorbed and desorbed were the same, which meant that 


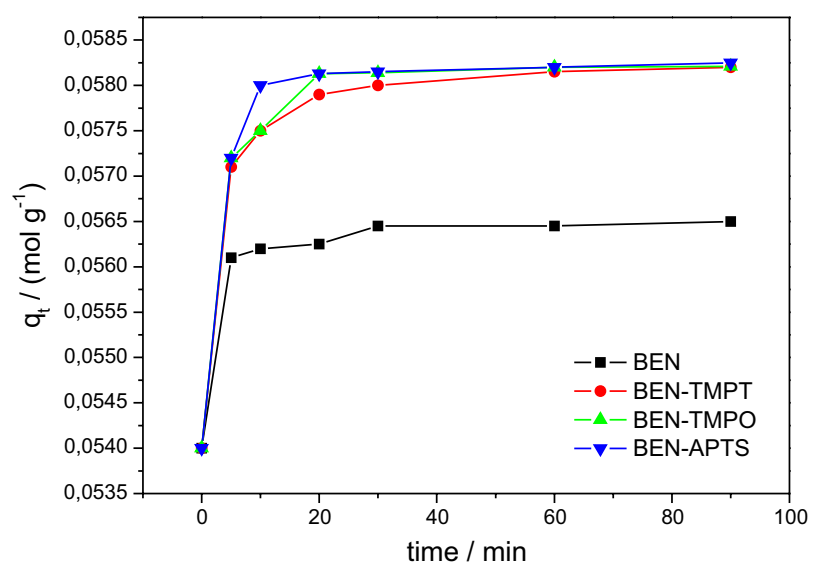

Figure 6. Adsorption kinetics study for BEN, BEN-APTS, BEN-TMPO, and BEN-TMPT. Experiments were conducted in $0.06 \mathrm{~mol} \mathrm{~L}^{-1} \mathrm{Cr}^{\mathrm{III}}$ solution.

the system achieved a state of dynamic equilibrium. ${ }^{45,46}$ Figure 6 showed that the functionalized samples presented increased adsorption capacity as compared with BEN. The presence of alkoxides in BEN, BEN-APTS, BEN-TMPT, and BEN-TMPO accounted for the increased adsorption capacity. The alkoxide type did not influence the amount of adsorbed $\mathrm{Cr}^{\mathrm{III}}$ ions, which indicated that only the terminal amino groups acted to remove $\mathrm{Cr}^{\mathrm{III}}$. The mechanism of adsorption may have involved exchangeable cations and amine groups. Indeed, FTIR analysis had revealed changes in $-\mathrm{NH}_{2}$ stretching, confirming that $\mathrm{Cr}^{\mathrm{III}}$ interacted with anime groups.

The increasing amount of amine groups in the alkoxide was not directly proportional to the amount of $\mathrm{Cr}^{\mathrm{III}}$ ions adsorbed onto bentonite. The adosrption capacity of the samples with one, two, and three amine groups increased by $3 \%$, which indicated that only the terminal amine groups bound to $\mathrm{Cr}^{\mathrm{III}}$ ions.

\section{Adsorption isotherms}

The qualitative and quantitative classification of isotherms depends on the isotherm shape, determines the mechanism of adsorption, and reflects the nature of adsorption. According to the models proposed by Giles et al. ${ }^{45}$ the isotherm obtained for BEN corresponded to an isotherm of the L-3 type, whereas the isotherms achieved for BEN-APTS, BEN-TMPT, and BEN-TMPO were of the $\mathrm{S} 2$ type (Langmuir isotherm). L-type isotherms reflect relatively high affinity of the metal for the clay surface. ${ }^{47,48}$ According to the model proposed by Langmuir, a $\mathrm{Cr}^{\text {III }}$ monolayer adsorbed onto the sites homogeneously distributed on the surface of solid BEN. Regarding BEN-APTS, BEN-TMPT, and BEN-TMPO, the model pointed to a spherical site where cation exchange improved in the presence of the alkoxides APTS/TMPO/TMPT.
At $\mathrm{Cr}^{\mathrm{III}}$ concentrations above $0.015 \mathrm{~mol} \mathrm{~L}^{-1}$, saturation started, which corresponded to formation of a second monolayer. This agreed with the proposed theoretical model because adsorption of the metal reached equilibrium. Hamdaoui and Nafrechoux ${ }^{46}$ and Kocaoba ${ }^{49}$ verified similar behavior for other functionalized materials in which the functionalization process did not significantly alter the adsorption mechanism. As displayed in Table 3 , the quantitative results revealed that functionalization promoted $\mathrm{Cr}^{\mathrm{III}}$ adsorption: BEN-APTS, BEN-TMPO, and BEN-TMPT had higher $\mathrm{q}_{\mathrm{e}}$ than BEN. Indeed, the presence of functional groups (amines) in the basal spacing of natural clays from the smectite group improved the cation exchange mechanism. According to the Pearson principle, the $\mathrm{NH}_{2}$ group is a soft base and can effectively interact with $\mathrm{Cr}^{\text {III }}$ ions, which are hard acids. This account for the high affinity constant of the complex obtained after the adsorption process $\left(\mathrm{BEN}-\mathrm{NH}_{2}-\mathrm{Cr}^{\mathrm{III}}\right)$ and justifies the increased maximum adsorption capacity of BEN-APTS, BEN-TMPO, and BEN-TMPT.

Table 3. Maximum adsorption capacity $\left(\mathrm{q}_{\mathrm{e}}\right)$ obtained from the experimental isotherms of BEN, BEN-APTS, BEN-TMPO, and BENTMPT in the presence of $\mathrm{Cr}^{\mathrm{III}}$ solution

\begin{tabular}{lc}
\hline Adsorbent & $\mathrm{q}_{\mathrm{e}} /\left(\mathrm{mol} \mathrm{g}^{-1}\right)$ \\
\hline BEN & 0.08850 \\
BEN-APTS & 0.09624 \\
BEN-TMPO & 0.09761 \\
BEN-TMPT & 0.09739 \\
\hline
\end{tabular}

\section{Adsorption efficiency}

Figure 7 illustrates the adsorption efficiency results for BEN, BEN-APTS, BEN-TMPO and BEN-TMPT.

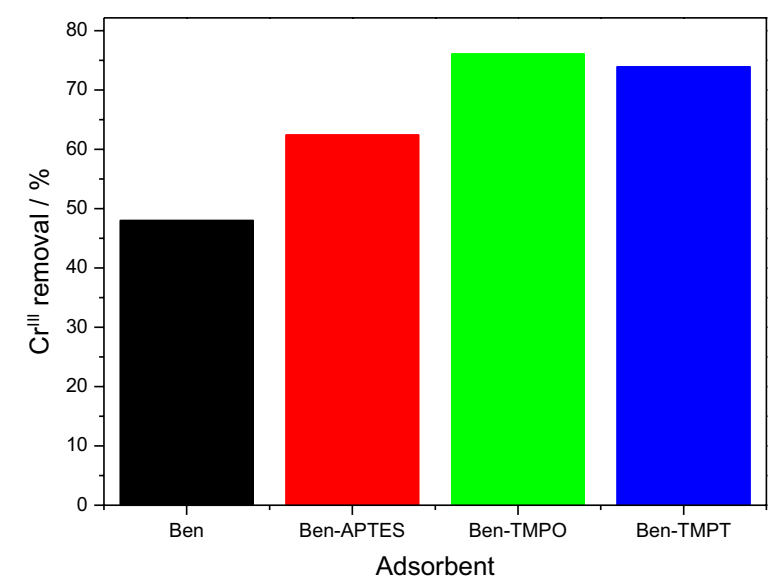

Figure 7. Percentage of $\mathrm{Cr}^{\mathrm{III}}$ removal by BEN, BEN-APTES, BEN-TMPO and BEN-TMPT.

The concentration maximum of the experimental isotherm allowed for calculation of the removal rate. $\mathrm{Cr}^{\mathrm{III}}$ had 
great affinity for the samples. Functionalization of BEN with alkoxides bearing $\mathrm{NH}_{2}$ groups yielded better results: removal rates of up to $74 \%$, as compared with $50 \%$ provided by BEN.

\section{Conclusion}

Commercial bentonite, an inexpensive material successfully employed for environmental remediation purposes, can be functionalized with alkoxides, to yield hybrid materials with potential application in $\mathrm{Cr}^{3+}$ ions adsorption, as confirmed by XRD, FTIR, TGA/DTG, and BET characterization techniques. The present results expand the possibility of applying hybrid technology in several areas of science and materials technology. Functionalization increases the capacity of bentonite to retain $\mathrm{Cr}^{\mathrm{IIII}}$ from 50 to approximately $70 \%$, which paves the way for new uses of this clay.

In conclusion, a natural clay submitted to no previous purification and treated with alkoxide can be used to remove metal ions from effluents. Although the efficiency of the materials studied herein to retain $\mathrm{Cr}^{\text {III }}$ ions is small, this is by no means a discouraging result. This is an initial work and many parameters remain to be investigated and optimized.

\section{Acknowledgments}

The authors acknowledge Conselho Nacional de Desenvolvimento Científico e Tecnológico (CNPq), Coordenação de Aperfeiçoamento Pessoal de Nível Superior (CAPES) and Fundação de Amaparo a Pesquisa do Estado de São Paulo (FAPESP) for support of this work.

\section{References}

1. Afzal, S.; Shahzada, K.; Fahad, M.; Saeed, S.; Ashraf, M.; Constr. Build. Mater. 2014, 66, 403.

2. Gupta, S. S.; Bhattacharyy, K. G.; Adv. Colloid Interface Sci. 2011, 162, 39.

3. de Faria, E. H.; Ciuffi, K. J.; Marçal, L.; Rocha, L. A.; Calefi, P. S.; Nassar, E. J.; Pepe, I.; Rocha, Z.; Vicente, M. A.; Trujillano, R.; Gil, A.; Korili, S.; ACS Appl. Mater. Interfaces 2012, 4, 2525.

4. Leonel, E. C.; de Faria, E. H.; Pimentel, R. C.; Nassar, E. J.; Ciuffi, K. J.; dos Reis, M. J.; Calefi, P. S.; Quim. Nova 2012, 35, 1407.

5. Sarakha, L.; Forano, C.; Boutinaud, P.; Opt. Mater. (Amsterdam, Neth.) 2009, 31, 562.

6. Bizaia, N.; de Faria, E. H.; Ricci, G. P.; Calefi, P. S.; Nassar, E. J.; Castro, K. A. D. F.; Nakagaki, S.; Ciuffi, K. J.; Trujillano, R.; Vicente, M. A.; Gil, A.; Korili, S.; ACS Appl. Mater. Interfaces 2009, 1, 2667.
7. Avila, L. R.; de Faria, E. H.; Ciuffi, K. J.; Nassar, E. J.; Vicente, M. A.; Trujillano, R.; Calefi, P. S.; J. Colloid Interface Sci. 2010, 341, 186.

8. Yang, S.-K.; Nam, J.-W.; Kim, Y.; Bull. Korean Chem. Soc. 2014, 35, 1218.

9. Zhu, H.; Du, M. L.; Zou, M. L.; Xu, C. S.; Fua, Y. Q.; Dalton Trans. 2012, 41, 10465.

10. Feuillie, C.; Daniel, I.; Michot, L. J.; Pedreira-Segade, U.; Geochim. Cosmochim. Acta 2013, 120, 97.

11. Tireli, A. A.; Marcos, F. C. F.; Oliveira, L. F.; Guimarães, I. R.; Guerreiro, M. C.; Silva, J. P.; Appl. Clay Sci. 2014, 97-98, 1.

12. Guimarães, A. M. F.; Ciminelli, V. S. T.; Vasconcelos, W. L.; Appl. Clay Sci. 2009, 42, 410.

13. Marçal, L.; de Faria, E. H.; Nassar, E. J.; Trujillano, R.; Martín, N.; Vicente, M. A.; Rives, V.; Gil, A.; Korili, S. A.; Ciuffi, K. J.; ACS Appl. Mater. Interfaces 2015, 7, 10853.

14. Bandeira, L. C.; Calefi, P. S.; Ciuffi, K. J.; Nassar, E. J.; Vicente, M. A.; Trujillano, R.; Polym. Int. 2012, 61, 1170.

15. Avila, L. R.; de Faria, E. H.; Ciuffi, K. J.; Nassar, E. J.; Calefi, P. S.; Vicente, M. A.; Trujillano, R.; J. Colloid Inter. Sci. 2010, 341, 186.

16. Sanchez, C.; Boissiere, C.; Cassaignon, S.; Chaneac, C.; Durupthy, O.; Faustini, M.; Grosso, D.; Laberty-Robert, C.; Nicole, L.; Portehault, D.; Ribot, F.; Rozes, L.; Sassoye, C.; Chem. Mater. 2014, 26, 221.

17. de Faria, E. H.; Lima, O. J.; Ciuffi, K. J.; Nassar, E. J.; Vicente, M. A.; Trujillano, R.; Calefi, P. S.; J. Colloid Inter. Sci. 2009, $335,210$.

18. Esteves, A. C. C.; Barros-Timmons, A.; Trindade, T.; Quim. Nova 2004, 27, 798.

19. Sanchez, C.; Rozes, L.; Ribot, F.; Laberty-Robert, C.; Grosso, D.; Sassoye, C.; Boissiere, C.; Nicole, L.; C. R. Chim. 2010, 13, 3.

20. Sanchez, C.; Belleville, P.; Popalld M.; Nicole, L.; Chem. Soc. Rev. 2011, 40, 696.

21. Rogez, G.; Massobrio, C.; Rabu, P.; Drillon, M.; Chem. Soc. Rev. 2011, 40, 1031.

22. Marçal, L.; de Faria, E. H.; Saltarelli, M.; Calefi, P. S.; Nassar, E. J.; Ciuffi, K. J.; Trujillano, R.; Vicente, M. A.; Korili, S. A.; Gil, A.; Ind. Eng. Chem. Res. 2011, 50, 239.

23. Nassar, E. J.; Nassor, E. C. O.; Ávila, L. R.; Pereira, P. F. S.; Cestari, A.; Luz, L. M.; Ciuffi, K. J.; Calefi, P. S.; J. Sol-Gel Sci. Technol. 2007, 43, 21.

24. Nassar, E. J.; Messaddeq, Y.; Ribeiro, S. J. L.; Quim. Nova 2002, 25, 27.

25. Yukselen, Y.; Kaya, A.; Eng. Geol. 2008, 102, 38.

26. Karapinar, N.; Donat, R.; Desalination 2009, 249, 123.

27. Sasikala, S.; Meenakshi, S.; Bhat, S. D.; Sahu, A. K.; Electrochim. Acta 2014, 135, 232.

28. Wu, P.; Wu, W.; Xing, N.; Zhu, N.; Lm, I. P.; Wu, J.; J. Hazard. Mater. 2009, 169, 824. 
29. Dogan, M.; Turhan, Y.; Alkan, M.; Namli, H.; Turan, P.; Demirbas, O.; Desalination 2008, 230, 248.

30. Li, J.; Miao, X.; Hao, Y.; Zhao, J.; Sun, X.; Wang, L.; J. Colloid Inter. Sci. 2008, 318, 309.

31. Nassar, E. J.; Neri, C. R.; Calefi, P. S.; Serra, O. A.; J. Non-Cryst. Solids 1999, 247, 124.

32. de Faria, E. H.; Ciuffi, K. J.; Nassar, E. J.; Vicente, M. A.; Trujillano, R.; Calefi, P. S.; Appl. Clay Sci. 2010, 48, 516.

33. Bertella, F.; Pergher, S. B. C.; Microporous Mesoporous Mater. 2015, 201, 116.

34. Bertagnolli, C.; da Silva, M. G. C.; Mat. Res. 2012, 15, 253.

35. Vieira, M. G. A.; Almeida Neto, A. F.; Gimenes, M. L.; Silva, M. G. C.; J. Hazard. Mater. 2010, 177, 362.

36. Leite, I. F.; Raposo, C. M. O.; Silva, S. M. L.; Cerâmica 2008, $54,303$.

37. Zivica, V.; Palou, M. T.; Composites, Part B 2015, 68, 436.

38. Lowell, S.; Shields, J. E.; Thomas, M. A.; Thommes, M.; Characterization of Porous Solids and Powders: Surface Area, Pore Size and Density, $1^{\text {st }}$ ed.; Klumer Academic Publishers: Netherlands, 2004.

39. Eren, E.; J. Hazard. Mater. 2009, 165, 63.

40. Ijagbemi, C. O.; Baek, M. H.; Kim, D. S.; J. Hazard. Mater. 2010, 174, 746 .
41. El Miz, M.; Akichouh, H.; Salhi, S.; El Bachiri, A.; Tahani, A.; IOSR J. Appl. Chem. 2014, 7, 60.

42. Hang, P. T.; Brindley, G. W.; Clays Clay Miner. 1970, 18, 203.

43. Bertagnolli, C.; da Silva, M. G. C.; Mat. Res. 2012, 15, 253.

44. Guarino, A. W. S.; Gil, R. A. S. S.; Polivanov, H.; Menezes, S. M. C.; J. Braz. Chem. Soc. 1997, 8, 581.

45. Giles, C. H.; Smith, D.; Huitson, A.; J. Colloid Inter. Sci. 1974, 3,755 .

46. Hamdaoui, O.; Nafrechoux, E.; J. Hazard. Mater. 2007, 147, 381.

47. Veeresha, H.; Tripathya, S.; Chaudhuria, D.; Hartb, B. R.; Powellb, M. A.; Appl. Geochem. 2003, 18, 1723.

48. Yun, L.; Xing, S.; Qiming, X.; Haidong, C.; Huixian, Z.; Shixiang, G.; J. Hazard. Mater. 2006, B137, 1149.

49. Kacaoba, S.; J. Hazard. Mater. 2007, 147, 488.

Submitted: October 20, 2015

Published online: December 10, 2015

FAPESP has sponsored the publication of this article. 